\title{
TESTIMONIATGE, ACTUALITZACIÓ I FABULACIÓ: LA MEMÒRIA HISTÒRICA DE LA GUERRA CIVIL EN LA NARRATIVA CATALANA ACTUAL
}

\author{
TESTIMONY, UPDATING AND STORYTELLING: \\ THE HISTORICAL MEMORY OF SPANISH CIVIL WAR \\ IN CONTEMPORARY CATALAN LITERATURE
}

\author{
JoAquim Espinós FeLIPE \\ Universitat d'Alacant \\ ximo.espinos@ua.es
}

Resum: El tema de la Guerra Civil i la dictadura franquista ha generat a l'Estat espanyol des de mitjans dels noranta ençà una quantitat ingent de novel-les, articles periodístics, investigació històrica i producció audiovisual que palesa la vigència problemàtica del tema. Aquest article vol centrar-se en un aspecte d'aquesta producció: la referida a les narracions que dintre de la literatura catalana actual l'han abordat. Es tracta d'un corpus d'obres extens en el qual han participat alguns dels escriptors més destacats. La nostra aproximació pretén estudiar aquesta vasta i diversa producció, mirant d'esbrinar les motivacions i els plantejaments narratius que regeixen aquestes propostes. Hi hem discernit tres models bàsics d'aproximació: el testimonial, l'actualitzador i el fabulador, i ho hem il-lustrat amb les obres que considerem més representatives. Així mateix, hi hem constatat un canvi pel que fa al model de representació de personatges i fets històrics, que tendeix al multiperspectivisme i a una visió més crítica. Aquest canvi es relaciona amb el debat públic que el moviment de recuperació de la memòria històrica ha produït a tot l'Estat espanyol.

Paraules clau: literatura catalana, literatura actual, novel-la, memòria històrica, Guerra Civil Espanyola, Dictadura franquista.

Abstract: Since the mid-nineties onwards, the theme of the Civil War and Franco's Dictatorship has generated in Spain an enormous number of novels, newspaper articles, historical research papers and audiovisual production that highlight the problematic relevance of the theme in the present time. This article focuses on one aspect of this production: those narrations that within Catalan literature have addressed it. It is an extensive body of works in which some of the most outstanding writers have been involved. Our approach aims to study this vast and diverse produc- 
JoAQuim Espinós Felipe

Testimoniatge, actualització i fabulació: la memòria històrica

de la Guerra Civil en la narrativa catalana actual

tion, trying to figure out the motivations and narrative approaches that govern these proposals. We've discerned three basic models: the testimonial, the updater and the storyteller, and we have exemplified them with the works that we have considered the most representative. Likewise, we have identified a change regarding the model of representation of historical characters and events, which tends towards multiperspectivism and a more critical vision. This change is related to the public debate that the movement of recovery of historical memory has generated throughout Spain.

Key words: Catalan literature, contemporary literature, novel, historical memory, Spanish Civil War, Franco's dictatorship.

\section{$\operatorname{cosects}$}

\section{NOVEL·LES CONTRA L'OBLIT}

Entre finals del segle xx i inicis del xxI sorgeix a l'Estat espanyol un interés extraordinari per la memòria de la Guerra Civil i la dictadura franquista, constatable tant en els articles periodístics com en la crítica literària i cultural (Colmeiro 2005: I3-15). El pacte de silenci que durant la transició havia convertit aquest tema en tabú donà pas a una constant reflexió que impregnà el debat ideològic del moment. Aquest fet, unit a la creació l'any 2000 de l'Asociación para la Recuperación de la Memoria Histórica i en el 2006 del seu equivalent català, posava en evidència que existien encara importants deutes pendents en la societat espanyola respecte al seu passat franquista. La Llei de la Memòria Històrica promulgada pel govern socialista el 2007 fou la culminació de tot aquest procés de qüestionament de la manera com es van gestionar durant la transició democràtica les responsabilitats del règim anterior.

La creació literària i cinematogràfica no fou aliena a tot aquest fenomen, i tot i que des de la transició el tema de la guerra i la postguerra havia estat present a tot l'estat espanyol, ara s'intensifica de manera significativa. Tal i com ha estat observat per diversos estudiosos (Colmeiro 2005: 22; Resina 2007: 407), es pot considerar l'esplet recent de novel.les i films sobre la guerra com un símptoma compensatori del fracàs en l'elaboració del trauma col-lectiu ocasionat per la guerra i el franquisme. La mediació artística, i en especial la ficció, tal i com ha estat observat des de la teoria de la postmemòria encunyada per Marian Hirsch (1993), demostra ser un mitjà més útil per a elaborar el trauma que no el relat històric.

El tema de la Guerra Civil Espanyola ocupa un lloc central en les lletres catalanes, $i$ les ones expansives d'aquell cataclisme arriben encara fins a l'actualitat. No resulta 
Joaquim Espinós Felipe

Testimoniatge, actualització i fabulació: la memòria històrica de la Guerra Civil en la narrativa catalana actual

gens estrany, a causa de la seua transcendència històrica, que va fer perillar fins i tot la mateixa supervivència nacional de Catalunya. La producció de relats sobre el tema començà en els mateixos anys de la guerra, tal i com assenyala Maria Campillo (I982: 9-I7). Revistes i periòdics demanaven relats que foren, essencialment, testimoniatges verídics i humans, en forma de crònica o «impressions en campanya», l'exemple més reeixit del qual serien les Unitats de xoc de Pere Calders, publicat en forma de llibre el 1938. Una vegada acabada la guerra, el degoteig de novel.les inspirades en l'experiència bèl.lica fou constant. Hi figuren obres com Tres a la reraguarda (1940), de C. A. Jordana; Xabola (1943), d'Agustí Bartra, o 556 Brigada Mixta (1945) d'Avel.lí Artís Gener, totes publicades a l'exili americà a causa de la censura ideològica i lingüística imposada en l'Espanya franquista. A partir de 1955 ja es publicaren a l'interior de Catalunya i la seua simple enumeració ocuparia una espai més que considerable (Faulí 1999; Mesalles 2002: 26I-353). Tan sols destacarem el lloc preeminent que hi ocupen Incerta glòria (1956), de Joan Sales i La plaça del Diamant (1962), de Mercè Rodoreda, així com la constància de Vicenç Riera Llorca i Manuel de Pedrolo en el tractament del tema. Cal destacar, a més, que a les obres dels autors que visqueren la guerra com a adults se sumen les dels que la visqueren com a infants, com ara Blai Bonet, Ramon Folch i Camarasa o Estanislau Torres. A aquests s'afigen, ja en la dècada dels setanta, els autors nascuts després de la guerra, com Terenci Moix, Montserrat Roig, M. Antònia Oliver o Josep Piera, que inauguren una altra manera de tractar el tema, posant especial èmfasi en l'educació repressiva que van haver de passar durant la postguerra (Espinós 20I8). Si bé la instauració de la democràcia implicà un augment de la publicació de narracions i especialment de textos memorialístics sobre el tema, és a mitjans de la dècada dels noranta que, al caliu del moviment de reivindicació de la memòria històrica, es produeix un punt d'inflexió. Als autors de generacions anteriors se n'incorpora una de nova: la dels néts dels que van patir la guerra, que se senten legitimats per a parlar-ne sense pors ni complexos i demanen respostes al silenci imposat pels pares i avis. A aquestes legítimes reivindicacions cal afegir que la indústria cultural de l'Estat espanyol veié en la memòria històrica un filó força rendible, i això fomentà l'aproximació al tema d'escriptors que fins aleshores no s'hi havien interessat. Siga com siga, la publicació de novel.les sobre la guerra i la postguerra augmentà considerablement en aquells anys, i convocà alguns dels més destacats autors de les lletres catalanes. Crida l'atenció, en aquest sentit, la concentració entre els anys 2003 i 2004 d'obres tan rellevants com Pa negre d'Emili Teixidor, La meitat de l'ànima de Carme Riera i Les veus del Pamano de Jaume Cabré. En els anys successius, i fins l'actualitat, el ritme de publicacions ha minvat, però s'ha mantingut de manera significativa. Des de l'any 1995 fins al 2018 hem consignat més de vuitanta

Caplletra 66 (Primavera, 2019), p. 33-52 
Joaquim Espinós Felipe

Testimoniatge, actualització i fabulació: la memòria històrica

de la Guerra Civil en la narrativa catalana actual

novel.les. ${ }^{1}$ És en aquest període que volem centrar en nostre estudi, amb la voluntat de discernir les principals característiques de les aproximacions actuals a la guerra i la postguerra. Considerem que, malgrat les dificultats d'abastar un corpus d'obres tan gran, la magnitud del fenomen bé mereix un esforç interpretatiu, que potser puga servir d'estímul i orientació a estudis monogràfics posteriors. En la nostra opinió, són tres els tractaments novel-lístics de la Guerra Civil i la postguerra que predominen en la literatura catalana actual: el testimonial, l'actualitzador i el fabulador. El testimonial és el més continuista respecte a l'emprat pels autors contemporanis de la guerra. Els altres dos, en canvi, resulten privatius de les generacions posteriors. El que anomene actualitzador intenta comprendre el drama viscut des de les circumstàncies pròpies del temps històric de l'escriptor, per a mirar de superar el trauma històric causat i retre justícia a les víctimes. El model fabulador, finalment, deixa de banda les derivacions polítiques i ideològiques per tal de potenciar els aspectes purament ficcionals. Aquest darrer suposa, doncs, el grau màxim de distanciament imaginatiu respecte al referent històric. Mirarem d'il.lustrar a continuació cada model narratiu amb les obres que considerem més significatives, encara que inevitablement deixarem fora aportacions importants. Cal remarcar que es tracta d'etiquetes no excloents, ja que sovint trobem obres que comparteixen diversos trets de cada model.

\section{LES NOVEL·LES TESTIMONIALS}

El model testimonial ha estat el dominant en les novel-les catalanes escrites pels escriptors que van viure directament els fets. En la majoria de casos tenien una inspiració autobiogràfica més o menys ficcionalitzada. Al llarg de la postguerra, com ja hem apuntat, la successió de novel-les sobre el conflicte civil ha estat constant, i el seu predomini testimonial ha permés a Josep Faulí dedicar un capítol del que fins ara és l'únic estudi de conjunt sobre el tema, titulat significativament "Crònica», a documentar amb citacions literàries diversos aspectes de la història i l'estat d'ànim col-lectiu de la societat catalana durant la Guerra Civil, la postguerra i l'exili (Faulí 1999: 27-92).

Algunes de les aproximacions actuals al tema mantenen aquesta voluntat documental i de testimoniatge, i donen, doncs, continuïtat al motlle narratiu emprat

I. Veure l'apèndix I. Hi hem exclòs la narrativa juvenil, les reedicions i la narrativa curta. La narrativa juvenil també s'ha ocupat profusament del tema. Vegeu l'estudi que li dediquen Margarita Prats (2002) i Caterina Valriu (20I3). Per a les també abundants aproximacions teatrals al tema vegeu Biel Sansano (20I4). 
pels autors de postguerra. Es tracta d'autors que no visqueren directament els fets narrats, tot i que en alguns casos, com el de Jordi Coca o Rafel Arnal, el successos pertanyen a la seua història familiar, $\mathrm{i}$ es podrien encabir dintre dels paràmetres de la postmemòria. Narratològicament, es tracta d'obres ambientades en el temps de la guerra o la postguerra, i amb una veu narrativa situada també en un moment històric simultani o pròxim de la matèria narrada. Exemplificarem aquest model narratiu amb les novel.les Sota la pols (200I) i La noia del ball (2007) de Jordi Coca, Barcelona cau (20I2), de Valentí Puig, i La solsida (200o), de Rafel Arnal, que complementarem amb alguna al.lusió a Pa negre (2003), d'Emili Teixidor. ${ }^{2}$

Sota la pols, de Jordi Coca, narra les seqüeles de la guerra en la Barcelona dels anys quaranta. El narrador, tal i com s'esdevé en Pa negre, és un home que evoca la seua infantesa, tot i que en aquest cas el temps de l'enunciació, amb el seu correlat valoratiu, adquireix un relleu menor. En tots dos casos se segueix el model de la novella d'aprenentatge. Si en la d'Emili Teixidor el nen esdevé un monstre, en aquesta la pèrdua de la innocència es manifesta en el descobriment de la seua ambivalència moral, evidenciada en els sentiments d'amor-odi vers un pare autoritari. Malgrat la seua escassa experiència biogràfica de la guerra, aquesta li ha deixat una petjada traumàtica profunda, expressada en malsons, lapsus de memòria i un sentiment de culpa ocasionat per l'afusellament de l'avi patern, militant anarquista. Aquest trauma fundacional es veu agreujat pel silenci imposat per la família, i la por a les represàlies. A la mort de l'avi s'ha de sumar la d'un germà als pocs mesos de nàixer, a causa d'una meningitis, $\mathrm{i}$ el suïcidi d'un amic. Tot plegat influeix en la conformació d'un caràcter apàtic i malenconiós, que sovint s'inhibeix del que passa al seu voltant i fins i tot es planteja la idea del suïcidi. Juntament a l'experiència interior del nen, la novel.la ens mostra també la vida de la Barcelona de l'època en un barri popular, el del Clot, dominada per la misèria i la repressió. La resta de personatges del barri viuen en una situació semblant de necessitat i opressió. La noia del ball complementa l'univers narratiu de Sota la pols. Ara la narradora serà la mare del protagonista i narrador, que al seu torn hi farà de narratari. Tota la novel.la s'estructura com un llarg monòleg adreçat al seu fill, en què la mare evoca els records d'infantesa i joventut. El temps històric narrat va dels anys vint a la immediata postguerra, just on comença Sota la pols, i la ingènua veu de la protagonista ens va deixant constància, de manera àgil i versemblant, dels esdeveniments més rellevants d'aquells anys: l'arribada de la República, el clima de convulsió política i cultural i la violència als carrers, la guerra, la repressió de rereguarda

2. D’altres obres que seguirien aquest format serien Guerres perdudes (1997), de Francesc Bodí i El fil de plata (1999), de Lluís-Anton Baulenas.

Caplletra 66 (Primavera, 2019), p. 33-52 
Joaquim Espinós Felipe

Testimoniatge, actualització i fabulació: la memòria històrica

de la Guerra Civil en la narrativa catalana actual

anarquista, els enfrontaments entre els anarquistes i la Generalitat, els bombardejos, l'entrada de les tropes franquistes a Barcelona, la brutal repressió posterior, que inclou la mort del seu sogre, que a Sota la pols era una presència fantasmal. El discurs del personatge, com s'esdevenia amb el del narrador de Sota la pols, explicita els efectes del trauma de la guerra, especialment dels bombardejos, i reitera sovint la seua incapacitat per a comprendre la desmesura dels fets patits. D'altra banda, la peripècia personal i la històrica s'imbriquen de manera íntima, i esdevenen un tot indissoluble en el record de la protagonista, que pensa que la violència del seu marit, la violència de la guerra i la violència feixista constitueixen una única realitat.

Barcelona cau, de Valentí Puig, mostra una visió molt crítica respecte als darrers dies de la Barcelona republicana. El protagonista i personatge focalitzat és Víctor, un jove agent del SIM que exerceix d'espia doble al servei de la cinquena columna. És un personatge al límit de l'amoralitat, que intenta treure profit de la situació per a enriquir-se i gaudir de tantes dones com puga. L'ambigüitat moral del personatge protagonista s'aparta del maniqueisme present en moltes de les novel.les catalanes inspirades en la Guerra Civil, que tendeixen a emfasitzar els atributs morals positius dels personatges del bàndol republicà i els negatius del bàndol nacional. Pel que fa al relat dels fets històrics, aquesta obra s'allunya també de la mistificació de la derrota republicana present a la majoria de novel.les, ja que el narrador no hi destaca l'èxode i el patiment dels perdedors, sinó el caos i la llei de la selva que regnava a Barcelona -i per extensió a Catalunya. I pel que fa a la valoració ideològica, no veu diferències entre els exèrcits enfrontats: «La rapinya tumultuosa havia començat $i$, entre dos leviatans, l'un en retirada i l'altre avançant, la ciutat buscava un sac de sucre» (Puig 20I2: 99). Tot $i$ les opinions vessades per l'autor en alguna entrevista sobre la seua oposició al revisionisme històric propugnat per la dreta espanyola i representat per autors com Pío Moa, afirmacions com aquestes l'hi aproximen, o si més no, fan pensar en una certa equidistància pel que fa a la responsabilitat històrica dels dos bàndols en conflicte (Massot 20I2).

No volem cloure aquest apartat dedicat a les novel.les testimonials sense referir-nos a les propostes narratives que se situen en un terreny fronterer entre la ficció i diverses modalitats de la no ficció. Ho il.lustrarem amb La solsida, de Rafael Arnal. ${ }^{3}$ Ni novel.la estricta ni llibre d'història, se situa en un espai pròxim a la docunovel.la o l'assaig narratiu. Tot i que al llarg del text la inclinació republicana del narrador resulta

3. L'obra de Víctor G. Labrado, amb títols com La guerra de quatre (2004), Quan anàvem a l'estraperlo (20I0) i No mataràs (2015) també s'inclouria en aquest apartat. També hi podríem encabir obres com Agent 447. L'home que va detenir Lluis Companys (20II), de Gemma Aguilera. 
palesa, el to general és d'una marcada equanimitat, que li permet criticar també els excessos del bàndol fidel a la legalitat republicana. La solsida manifesta, doncs, una clara voluntat de testimoniatge, i no sols en els fets externs, sinó també en els novellescos. El protagonista, Ramon, és un jove emigrant extremeny que arriba a Tavernes Blanques, poble natal de l'autor, amb una mà davant i una altra darrere, embolicat amb la bandera republicana. Ramon resulta ser un personatge sense escrúpols, que canvia d'idees segons com bufe el vent: passa de llibertari a col-laboracionista, comunista, quintacolumnista i, finalment, feixista. La seua amoralitat resulta, doncs, comparable a la del protagonista de Barcelona cau.

\section{LES NOVEL·LES ACTUALITZADORES}

Si el model testimonial és continuista respecte a les novel-les de postguerra, els altres dos esquemes narratius que tractarem — l'actualitzador i el fabulador — resulten ja privatius de l'aproximació actual al tema. Els relats que anomene actualitzadors situen el temps de l'enunciació en els anys de la democràcia i el temps de la història en els anys de la guerra o la postguerra. Aquesta doble temporalitat implica també un desdoblament de l'estatus dels personatges i de les línies narratives. Sense arribar la majoria dels casos a la condició de «meta-memory texts» proposada per Ofelia Ferrán (2007: 59-65), ${ }^{4}$ però situant-se ben a prop, aquest tipus de relats permet reflexionar sobre el sentit dels fets passats i integrar la memòria de la guerra i el franquisme en el debat ideològic actual. Un altre tret freqüent en aquest tipus de relat és la seua metanarrativitat, ja que sovint s'hi fa palés el mateix procés de documentació i d'escriptura. Les novel.les actualitzadores han gaudit de certa fortuna a causa de la seua capacitat per a elaborar la memòria traumàtica i extraure'n significacions enriquidores per al present. Les novel.les que analitzarem per il.lustrar aquest model són Les veus del Pamano (2004), de Jaume Cabré — la que ha tingut una major repercussió nacional i

4. Al llibre Working through memory. Writing and Remembrance in Contemporary Spanish Narrative, Ofelia Ferrán estudia una sèrie de novel.les d'autors hispànics situades entre 1960 i el final de segle: El largo viaje, de Jorge Semprún; Volverás a Región, de Juan Benet; Memoria de la melancolía, de M. Teresa León; L’hora violeta, de Montserrat Roig, i El jinete polaco d'Antonio Muńoz Molina. Tal com indica l'autora a la introducció, es tracta de textos que configuren una pràctica autoreflexiva que pot servir de model per a desenvolupar la cultura de la memòria que encara manca en l'Espanya actual.

Caplletra 66 (Primavera, 2019), p. 33-52 
Joaquim Espinós Felipe

Testimoniatge, actualització i fabulació: la memòria històrica

de la Guerra Civil en la narrativa catalana actual

internacional—i La col.laboradora (20I2), d'Empar Moliner — que manté una actitud més crítica vers la tendència literària i el moviment de la memòria històrica. ${ }^{5}$

Tal i com hem observat anteriorment (Espinós 2004: 8-9), Les veus del Pamano és una novel.la que conjumina la capacitat fabuladora — destacada també per autors com Jaume Aulet (2004: IIO) — amb la voluntat d'indagar des de l'actualitat en el sentit de la Guerra Civil. Els fets històrics que s'hi narren giren al voltant de la lluita que els maquis van dur a terme a l'acabament de la guerra en el poble de Torena, topònim imaginari d'un poble del Pallars. El personatge que protagonitza aquesta línia argumental és Oriol Fontelles, un mestre destinat al poble en els primers anys de la postguerra, que es veu embolicat, a contracor, en la repressió que els falangistes i la guàrdia civil duen a terme contra els maquis. Es tracta d'un personatge antiheroic, que practica un doble joc: tot i ser considerat un màrtir falangista, en realitat col-laborava amb els guerrillers. Molts anys després, ja en l'actualitat —any 200I-, Tina Bros, una altra mestra, descobrirà uns quaderns on figuren les cartes que Oriol Fontelles va escriure a la seua filla, amagades en l'escola del poble, i a partir d'ací iniciarà una recerca que la durà a conéixer la veritat dels fets. Tal i com observa Kathleen M. Glenn (2008: 50), la novel.la de Cabré evidencia com la versió oficial de la història, segrestada per les autoritats franquistes, oculta crims inconfessables. Mario Santana, per la seua part, hi afig "la necessitat de la reflexió crítica sobre les limitacions de la memòria» (Santana 20II: 58). L'estructura de la novel.la evidencia contínuament la interrelació entre el passat i el present, mitjançant l'ús de retrospeccions i juxtaposicions de plans narratius $i$ canvis en els punts de vista, fins i tot en una mateixa frase, que caracteritzen la prosa de l'autor.

Clourem aquest bloc de les narracions que tracten la problemàtica de la Guerra Civil des de la perspectiva actual amb una que hi adopta una actitud inèdita. Em referesc a La col.laboradora, d'Empar Moliner. La principal novetat que presenta aquesta novel.la rau en el tractament satíric. Certament, l'autora no fa sinó aplicar-hi el mateix to caricaturesc que a la resta de temes que ha abordat al llarg de la seua obra literària. Cal dir, però, que la crítica al moviment de la memòria històrica, tant en el seu vessant institucional com literari, s'insereix en una crítica general a la impostura que domina la societat contemporània, amb especial incidència en el món editorial

5. Semblant esquema narratiu presenten les novel-les La meitat de l'ànima (2004), de Carme Riera; L'home de l'estació (2004), de Joaquim González Caturla; On dormen les estrelles (2004), de Joan Garí, i Un home que sén va (20I4), de Vicenç Villatoro. També en la literatura castellana aquest model actualitzador resulta molt important, i compta amb obres tan rellevants i populars com Soldados de Salamina, de Javier Cercas; El jinete polaco, d'Antonio Muñoz Molina; Tu rostro mañana, de Javier Marías; El vano ayer, d'Isaac Rosa, o Enterrar a los muertos, d'Ignacio Martínez de Pisón. 
Joaquim Espinós Felipe

Testimoniatge, actualització i fabulació: la memòria històrica de la Guerra Civil en la narrativa catalana actual

i polític (Galves 2013: 26). El personatge que exerceix de protagonista i narradora treballa de «negra» per a una editorial, i aviat marca distàncies sobre el model de novelles que ací anomenem actualitzadores, tal i com es trasllueix en la següent afirmació (Moliner 20I2: 8):

[...] no vull explicar cap història de la Guerra Civil, i encara menys li vull explicar la vida d'una escriptora moderna, que seria jo, que se sent fascinada per una dona —una dona amb qui té molt en comú, més del que ella voldria, ja m’entén- que va viure molts anys enrere. Sé que ara es fan novel.les així, només aquest últim any se n’han publicat tres o quatre. Però jo no sóc ben bé escriptora i sobretot no sóc tan depravada.

L'actitud crítica es fa palesa tant en el desenvolupament argumental com en el tractament dels personatges. La trama gira al voltant de l'encàrrec que la Comissió per la Recuperació de la Memòria Històrica — l'al.lusió a l'associació real hi resulta ben clara - li fa a la protagonista per a treballar amb Paul Adams, famós hispanista que sembla inspirar-se en Ian Gibson o Paul Preston, al qual se li ha encarregat fer la biografia d'Antonieta Gelabertó Pedrola, una dona assassinada durant la Guerra Civil i soterrada en una fossa situada en unes vinyes pertanyents a una important bodega. L'escriptura del llibre va acompanyada de la construcció d'un monument que pretén homenatjar Antonieta, i amb ella totes les dones víctimes de la guerra. Tanmateix, els motius de l'encàrrec obeeixen més a interessos polítics que a raons ètiques: ho fan per a desactivar la indignació dels familiars de les víctimes, que farts de no veure ateses les seues demandes d'exhumació, li han llançat ous a la consellera de cultura. Per a acabar-ho d'adobar, els membres de la comissió no mantenen cap mena d'empatia ni respecte per la seua tasca. Tal i com ells mateixos confessen, en formen part per les substancioses dietes que perceben. D'altra banda, la biografia d'Antonieta Gelabertó resulta també molt poc exemplar. Tot i que en la versió oficial es presentarà com una víctima del feixisme, en realitat morí de manera ben poc heroica, víctima dels abusos sexuals d'un milicià republicà que la matà per tal d'encobrir el seu delicte. En definitiva, Empar Moliner menysté els aspectes positius del moviment de recuperació de la memòria històrica i posa l'èmfasi en la manipulació que els polítics i la indústria editorial hi poden exercir.

\section{LES NOVEL·LES FABULADORES}

El model fabulador, finalment, instrumentalitzaria el tema de la guerra i la postguerra com a motiu argumental, mitjançant la seua hibridació amb diversos gè- 
neres populars com la novel.la policíaca, la novel.la gòtica, el melodrama, la novel.la fantàstica o la llegenda. En algunes ocasions el component fabulador adquireix una importància tan gran que acaba per fagocitar la significació històrica, política o ideològica del tema tractat. En aquests casos ens trobaríem davant de la representació més explícita de la conversió del moviment de la memòria històrica en un negoci editorial al servei de la indústria de l'entreteniment. ${ }^{6}$ Les novel.les que hem triat per a il.lustrar aquest model fabulador són Per un sac d'ossos (2005), de Lluís-Anton Baulenas, i Crim de sang (2012), de Sebastià Alzamora. ${ }^{7}$

Començarem l'estudi d'aquesta secció amb Per un sac d'ossos, de Lluís-Anton Baulenas, tercera de les aproximacions de l'autor al tema de la Guerra Civil i la postguerra. ${ }^{8} \mathrm{El}$ material històric hi és tractat amb una potència fabuladora més que notable, amb clares picades d'ull a les tècniques del thriller i la novel-la d'aventures. L'argument gira al voltant de la venjança d'un jove, Ginés, el pare del qual està presoner al camp de concentració de Miranda de Ebro. Abans de morir, el pare li fa prometre que soterrarà Bartomeu Camús, un amic que jau en una fossa anònima en un bosc de les rodalies del camp de concentració. També li parla d'un tresor i li dona un sobre que conté el plànol amb un lloc marcat amb una creu. Després de la mort del pare, Ginés escapa de la Casa de la Caritat on estava internat, i acaba allistant-se a la legió. Juntament amb la seua adscripció a la novel.la policíaca i d'aventures, Per un sac d'ossos conté un fort element de denúncia de la dictadura franquista, vehiculat a través de la veu de Ginés, que hi exerceix de narrador. De vegades li resulta difícil distingir entre la imatge pública de legionari, amb la càrrega de brutalitat i adhesió al règim franquista que comporta, i la seua veritable personalitat, fidel als ideals republicans de son pare. Aquesta tensió

6. És potser en el mitjà televisiu on aquesta mercantilització de la memòria resulta més patent, amb l'emissió de telesèries que donen una visió edulcorada, en clau sentimental, de la postguerra. Títols com Temps de silenci, Cuéntame, Amar en tiempos revueltos o El tiempo entre costuras en serien bons exemples. En el format cinematogràfic es pot observar també aquesta tendència a potenciar el component sentimental. Fins i tot la potent indústria dels videojocs ha pres el tema de la Guerra Civil com a argument d'un dels seus productes. El videojoc Sombras de guerra, primer que pren la Guerra Civil com a motiu lúdic, seria un cas extrem d'aquesta mercantilització de la memòria històrica. Sobre les pel-lícules basades en les novel.les de Manuel Rivas, vegeu Dolores Vilavedra (20II). Sobre la impregnació sentimental del corrent mainstream de la memòria històrica, vegeu Jaume Peris Blanes (20II).

7. Dintre d'aquesta modalitat fabuladora es podrien encabir les novel-les Bulevard dels francesos (2010) i Ombres en la nit (2012), de Ferran Torrent; Dones d'aigua, hòmens de fang (2013), de Toni Cucarella; Les dones de la principal (20I4), de Lluís Llach; Trencatenebres (2015), de Juli Alandes; Les veus i la boira (2015), de Vicent Usó, i Jo sóc aquell que va matar Franco (20I8), de Joan-Lluís Lluís, així com el conte «El bosc», inclòs al volum Les edats d'or (200I), d'Albert Sánchez-Pinyol.

8. Les altres dues són Noms a la sorra (1995), que manté el mateix caire fabulador, i El fil de plata (I998), més pròxima al model testimonial. 
Joaquim Espinós Felipe

Testimoniatge, actualització i fabulació: la memòria històrica de la Guerra Civil en la narrativa catalana actual

interior acaba passant-li factura, en forma d'estranyament. Ginés es converteix, en definitiva, en una espècie de monstre, no massa allunyat del nen protagonista de $\mathrm{Pa}$ negre. Un altre tema important tractat a Per un sac d'ossos és el del robatori de nens a les preses republicanes, inserit com un element més de la trama.

En Crim de sang, de Sebastià Alzamora, el contingut ideològic resta també reduït al mínim, i el gènere policíac és de nou el model triat per a desenvolupar la trama, juntament amb el de terror. Aquesta darrera aportació conferix una gran originalitat a aquesta obra, que es fa palesa ja des del seu inici, en el fet que el personatge focalitzat és ni més ni menys que un vampir que confessa haver-se cobrat recentment dues víctimes. De la investigació d'aquests crims en el context de l'estiu del 1936 se n’ocuparà el comissari Gregori Muńoz, posseïdor dels atributs més reconeixibles del gènere negre. Una de les víctimes del suposat vampir és un germà marista que romania amagat en una pensió del carrer Ferran, tot fugint de la persecució dels anarquistes. I és precisament el món eclesiàstic i el de la FAI, amb el brutal Departament d'Investigació en primer terme, els que adquiriran un major protagonisme a l'obra. Al fil de les investigacions del comissari apareixen de manera recurrent una sèrie de temes en què s'endevinen els veritables interessos del novel.lista, i entre tots aquests, n'hi ha un que es repeteix significativament: el de l'existència d'una part monstruosa en l'ésser humà. El monstre humà emergeix col-lectivament en temps de guerra, i adopta al llarg de la novel.la diverses formes: el vampir, l'autòmat o el fanatisme, tant religiós com anarquista.

Antoni Maestre (2016) ha vinculat, de manera molt encertada, el buidament del significat històric i ideològic i la conseqüent potenciació de l'element fabulador, amb l'estètica postmoderna, tot relacionant la novel.la de Sebastià Alzamora amb el relat «El bosc» d'Albert Sánchez Piñol i el còmic La batalla de Madrid, de Rafael Jiménez i José A. Sollero. Aquesta simplificació o distorsió històrica pròpia del discurs postmodern hauria trobat en la política de consens que domina el discurs institucional espanyol un context propici per al seu arrelament.

\section{MULTIPERSPECTIVISME I QÜESTIONAMENT DELS PARADIGMES DE REPRESENTACIÓ}

Les novel.les que hem analitzat per il.lustrar els tres models narratius que considerem més representatius de la narrativa catalana recent que aborda el tema de la memòria històrica — el testimonial, l'actualitzador i el fabulador - comparteixen, per damunt dels seus diferents plantejaments narratius, un tret en comú: la problema-

Caplletra 66 (Primavera, 2019), p. 33-52 
JoAquim Espinós Felipe

Testimoniatge, actualització i fabulació: la memòria històrica

de la Guerra Civil en la narrativa catalana actual

tització a què sotmeten els models de representació dominants en les obres anteriors, tant pel que fa a la conformació dels personatges com pel que fa al tractament dels fets històrics. Cert que la tria de les novel-les no ha estat casual, perquè hem buscat, entre les moltes possibles, aquelles que implicaven un canvi significatiu en els paradigmes de representació. Aquesta obertura vers una major pluralitat de perspectives es pot observar en tot el polisistema hispànic. Així ho ha subratllat Hans Hansen (20II) en l'estudi que dedica a la literatura castellana recent, en la qual observa una modificació respecte al punt de vista axiològic, que abans del canvi de mil.lenni adoptava una actitud majoritàriament favorable al bàndol republicà. En les novel.les castellanes més recents Hansen apunta l'existència d'un multiperspectivisme que afecta tant la construcció dels personatges com la representació del mal en la causa republicana. El mateix podríem dir en el cas català. Pel que fa als personatges, el tret dominant en les obres que hem analitzat és l'absència d'idealitzacions. Els protagonistes, tot i formar part majoritàriament del bàndol republicà, ja no són els herois o víctimes d'una peça que podíem trobar en les novel.les anteriors. Un bon exemple d'aquesta major complexitat i subtilesa en la construcció dels personatges el trobem en el protagonista de Les veus del Pamano, Oriol Fontelles, considerat un màrtir falangista per la història oficial, quan en realitat colllaborava clandestinament amb els maquis. Semblant consideració mereix el protagonista de Barcelona cau, de Valentí Puig: agent del servei d'intel-ligència de la República i alhora col-laborador de la quinta columna feixista. Els personatges de la resta de novel-les presenten la mateixa ambigüitat essencial. Així, els nens de les novel.les de Jordi Coca i Emili Teixidor alberguen sentiments contradictoris a causa del trauma de la guerra. En el cas de Sota la pols, el converteixen en un adolescent depressiu; en el de Pa negre, en un monstre que renega dels seus orígens i es lliura incondicionalment a mans dels vencedors. En La solsida, de Rafael Arnal, el protagonista no ix molt millor parat: és un cínic que canvia d'idees i de bàndol segons li convinga. L'ambivalència moral — legionari i antifeixista— és també el tret més característic del protagonista de Per un grapat d'ossos, la novel.la de Lluís-Anton Baulenas.

Molt important resulta també, en aquesta ruptura amb el maniqueisme del punt de vista, el reconeixement dels esdeveniments negatius en la zona republicana. Així, la violència anarquista en els primers mesos de la guerra és un dels leit motiv de Crim de sang, i les tortures a les txeques comunistes, la persecució religiosa i la lluita per la supervivència en els darrers dies de la Catalunya republicana són exposades de manera crua a Barcelona cau. Les arbitrarietats comeses en la zona republicana ocupen també un espai rellevant a La solsida. 
Joaquim Espinós Felipe

Testimoniatge, actualització i fabulació: la memòria històrica de la Guerra Civil en la narrativa catalana actual

Especial esment mereix el cas de La col-laboradora, d'Empar Moliner. El que s'hi relativitza no és sols la idealització dels perdedors, sinó el mateix moviment de recuperació de la memòria històrica. L'escriptora protagonista pren distància respecte a la moda de les novel-les que hem anomenat actualitzadores, i critica, amb l'acidesa habitual en ella, el fet que la industria cultural les haja convertit en un objecte més de consum.

Cert que aquest multiperspectivisme pel que fa al tractament dels personatges i fets històrics no és un tret totalment inèdit en les lletres catalanes. En una novel.la clàssica sobre el tema com és Incerta glòria ja el trobàvem en un grau eminent. Es tracta, però, d'una excepció, i la seua complexitat, independència de criteri i manca de condescendència amb els perdedors ha estat una de les causes de la difícil recepció de l'obra de Joan Sales (Pla 20I2). La diferència és que en les novel.les actuals aquest multiperspectivisme s'ha normalitzat.

\section{A MANERA DE CONCLUSIÓ}

Després d'aquest recorregut per algunes de les obres més representatives de la narrativa actual sobre la Guerra Civil i la dictadura franquista, creiem que hem pogut dilucidar algunes qüestions significatives. En primer terme, la gran quantitat d'obres que se n'ocupen des de mitjan dels anys noranta ençà, a causa de l'impuls donat pel moviment de recuperació de la memòria històrica. Aquesta proliferació de relats demostra que la societat espanyola necessita encara una narrativa que conjure els efectes tòxics d'aquest trauma fundacional. Al mateix temps, l'èxit editorial d'aquesta temàtica ha creat un ambient propici perquè molts escriptors es decidesquen a dir-hi la seua.

En l'àmbit de la literatura catalana hem comptabilitzat més de vuitanta obres en el període que va de 1995 fins al 20I8. Malgrat que és de preveure que el període de major volum de publicacions s'haja produït ja, també cal esperar encara una successió d'obres en els pròxims anys. L'extensió d'aquest corpus d'obres fa molt difícil una panoràmica de conjunt, raó per la qual hem limitat el nostre estudi a aquelles obres que hem considerat més significatives, bé perquè pertanyen a alguns del noms més rellevants de la literatura catalana, bé per la seua singularitat.

Hem analitzat i classificat les novel-les tot atenent a la major o menor presència de components testimonials, actualitzadors i fabuladors. Mentre que el model testimonial resulta continuista respecte de les obres dels escriptors que van viure directament els fets, i aborda bé experiències personals o familiars de la guerra i la postguerra o bé episodis poc tractats, el model actualitzador i el fabulador representen de manera

Caplletra 66 (Primavera, 2019), p. 33-52 
Joaquim Espinós Felipe

Testimoniatge, actualització i fabulació: la memòria històrica

de la Guerra Civil en la narrativa catalana actual

genuïna les aproximacions actuals. En el model actualitzador es buscaria inserir el tema de la memòria històrica en el debat ideològic actual. En el fabulador, el tema de la Guerra Civil i la dictadura franquista s'hibridaria amb la literatura de gènere, obviant, en molts casos, les implicacions ideològiques o històriques i aproximant-se a la literatura de consum.

En la majoria d'obres que aborden el tema de la Guerra Civil i la postguerra abans del canvi de mil.lenni —és a dir, les escrites pels testimonis directes o pels seus fills_-, predomina un punt de vista més esbiaixat pel que fa al tractament dels personatges i al relat dels fets. L'arribada de la generació dels néts i amb ella del moviment de recuperació de la memòria històrica ha propiciat que en bona part de les obres escrites a partir de finals del segle $\mathrm{xx}$-les més innovadores $\mathrm{i}$, sovint, les més interessants - es produesca una obertura cap una major diversitat de perspectives, fruit de la distància crítica que hi han pogut establir els seus autors.

Joaquim Espinós Felipe Universitat d'Alacant ximo.espinos@ua.es

ORCID oooo-0003-4388-7636

\section{REFERÈNCIES BIBLIOGRÀFIQUES}

Aguilera, G. (20II) Agent 447. L'home que va detenir Lluís Companys, València, Edicions 3 i4.

Alzamora, S. (20I2) Crim de sang, Barcelona, Proa.

Arnal, R. (20II [ $\mathrm{I}^{\mathrm{a}}$ ed. 2000]) La solsida, Tavernes Blanques, L'Eixam.

Aulet. J. (2004) «Ressenyes», Els Marges, 74, p. I05-IIO.

Baulenas, Ll.-A. (1995) Noms a la sorra, Barcelona, Columna.

- (1998) El fil de plata, Barcelona, Columna.

- (2005) Per un sac d'ossos, Barcelona, Planeta.

Bertrand de Muñoz, M. (1996) «Novela histórica, autobiografía y mito (la novela y la guerra civil española desde la transición)», dins J. Romera Castillo, F. Gutiérrez Carbajo i M. García-Page, (ed.), La novela histórica a finales del siglo XX, Madrid, Visor, p. 19-38

Bodí, F. (1997) Guerres perdudes, Barcelona, Ed. 62.

Cabré, J. (2004) Les veus del Pamano, Barcelona, Proa.

Campillo, M. (1982) Contes de guerra i revolució (1936-1939), Barcelona, Laia. 
Coca, J. (200I) Sota la pols, Barcelona, Proa.

- (2007) La noia del ball, Barcelona, Proa.

Colmeiro, J. F. (2005) Memoria histórica e identidad cultural. De la postguerra a la postmodernidad, Barcelona, Anthropos.

Cucarella, T. (2013) Dones d'aigua, hòmens de fang, Alzira, Bromera.

Espinós, J. (2004) «Memòria i ficció. La guerra civil espanyola en la novel-lística catalana recent», Quadern, I46, p. 8-9.

— «A Generation without Memory? The Spanish Civil War as seen by the Catalan Generation of the I970s", Butlletin of Hispanic Studies, 95, Issue 8, p. 843-857.

Faulí, J. (1999) Novel.la catalana i guerra civil, Barcelona, Publicacions de l'Abadia de Montserrat.

Ferrán, O. (2007) Working through Memory. Writing and Remembrance in Contemporary Spanish Narrative, Lewisburg, Bucknell University Press.

GARí, J. (2005) On dormen les estrelles, Alzira, Bromera.

G. Caturla, J. (2005) L'home de l'estació, Alzira, Bromera.

G. LABrAdo, V. (2004) La guerra de quatre, Alzira, Bromera.

- (2010) Quan anàvem a l'estraperlo, Barcelona, Angle Editorial.

- (2015) No mataràs, Alzira, Bromera.

Hirtch, M. (2008) «The Generation of Postmemory», Poetics Today, 29,I, p. I03-I28. LlaCH, Ll. (20I2) Memòria d'uns ulls pintats, Barcelona, Empúries.

- (2014) Les dones de la principal, Barcelona, Empúries.

Galves J. (2013) «Moliner, impostura i veritat», Caràcters, 63, p. 26.

Glenn, K. M. (2008) «Reclaiming the past: Les veus del Pamano and Pa negre», Journal of Catalan Studies, p. 49-64.

Hansen, H. (20II) «Multiperspectivism in the Novels of the Spanish Civil War», Orbis Litterarum, 66/2, p. I48-I66.

Labanyi, J. (1989) Myth and History in the Contemporary Spanish Novel, Cambridge, Cambridge University Press.

Maestre, A. (2016) «From amnesia to fable: historical memory, pulp fiction and political consensus", Journal of Spanish Cultural Studies, 17,I, p. 27-43.

Massot, J. (20I2) «Valentí Puig: "En la guerra pierden todos”». [<www.lavanguardia. $\mathrm{com} /$ cultura/20I20II8/54244551307/valenti-puig-en-la-guerra-pierden-todos. html]

Mesalles, H. (2002): «Bibliografia de la memòria i ficció de la Guerra Civil espanyola en la literatura catalana», en Literatura de la guerra civil. Memòria i ficció, Institut d'Estudis Ilerdencs, Lleida, pp. 26I-353.

Moliner, E. (20I2) La col.laboradora, Barcelona, Columna. 
Joaquim Espinós Felipe

Testimoniatge, actualització i fabulació: la memòria històrica

de la Guerra Civil en la narrativa catalana actual

Peris Blanes, J. (20II) «Va haver-hi un temps no tan llunyà... Relats i estètiques de la memòria i ideologia de la reconciliació a Espanya», $452^{\circ} \mathrm{F}$. Revista electrònica de teoria de la literatura i literatura comparada, 4, p. 29-5I.

Pla, X. (20I2) «La glòria certa de Joan Sales», Via. Revista del Centre d'Estudis Jordi Pujol, I8, p. 5-I8.

Prats, M. (2002) «La representació literària de la guerra civil en la literatura infantil i juvenil de la dècada dels noranta», en Literatura de la guerra civil. Memòria $i$ ficció, Lleida, Institut d'Estudis Ilerdencs, p. 235-246.

Puig, V. (2012) Barcelona cau, Barcelona, Proa.

Resina, J. R. (2007) «Window of Opportunity: The Television Documentary a 'AfterImage' of the War", en Teaching Representations of the Spanish Civil War, a cura de Noël Vallis, The Modern Language Association of America, New York, p. 406-423.

Riera, C. (2004) La meitat de l'ànima, Barcelona, Proa.

Sales J. (1956) Incerta glòria, Barcelona, Aymà.

Santana, M. (20II) "Jaume Cabré: Les veus del Pamano i la novel.la de la memòria històrica», Journal of Catalan Studies, 20II, p. 47-59.

Sánchez Pinyol, A. (200I) Les edats d'or, Barcelona, Proa.

SANsANo, B. (2014) «De fosses i fantasmes. Memòria, trauma i identitat en l'escena catalana actual», Journal of Catalan Studies, 2014, p. 4-22.

Teixidor, E. (2003) Pa negre, Barcelona, Columna.

Torrent, F. (20Io) Bulevard dels francesos, Barcelona, Columna.

- (20II) Ombres en la nit, Barcelona, Columna.

VAlriu, C. (20I3) "Guerra Civil i narrativa juvenil catalana: testimoni i literatura», Revista de Filología Románica, 30, p. 309-323.

VIlavedra, D. (2OII) «Memoria y postmemoria: la elaboración literaria de la guerra civil en la narrativa gallega», en Diálogos transatlánticos. Memoria del II congreso internacional de literatura y cultura españolas contemporáneas, vol. II, UNLP, p. I-I2. [Edició on line]

Villatoro, V. (2014) Un home que sén va, Barcelona, Proa. 


\section{APÈNDIX I}

Exposem a continuació, sense ànim d'exhaustivitat, i ordenades per anys, les novel.les sobre la Guerra Civil i la postguerra publicades en la literatura catalana des de 1995 fins el 2018.

1995

Antoni Dalmau, Capsa de records.

Roser Caminals, Un segle de prodigis.

Ferran Torrent, Gràcies per la propina.

Joaquim Espinós, Ombres en el riu.

Lluís-Anton Baulenas, Noms a la sorra .

1996

Josep Lladonosa, Un toll de sang a terra.

Estanislau Torres, Entre el Clot i el Guinardó.

1997

Francesc Bodí, Guerres perdudes.

Francesc Aguiló, L'olor dels corretjams del Comte Rossi.

Miquel López Crespí, Estiu de foc. Dietari d'una miliciana.

Vicenç Villatoro, La claror del juliol.

Josep Coll, El segle de la llum.

Xavier Guillamon, El vent de dalt.

1998

Ada Castells, El dit de l'àngel.

Miquel Pairolí, El convit.

Josep Culell-Ramis, Senders d'atzar.

Josep Tomàs, Adéu, Bakunin.

1999

Lluís-Anton Baulenas, El fil de plata.

Miquel López Crespí, L’amagatall.

Llorenç Femenias, Cròniques malastres: on un poble tranquil recorda els mals somnis.

Glòria Llobet, El cor de les pedres.

Antoni Vidal, La mà del jardiner. 
Joaquim Espinós Felipe

Testimoniatge, actualització i fabulació: la memòria històrica de la Guerra Civil en la narrativa catalana actual

2000

Rafael Arnal, La solsida.

Miquel López Crespí, Núria i la glòria dels vençuts.

Jordi Teixidor, Cromos:històries de Barcelona.

Gabriel Janer Manila, Estàtues sobre el mar.

Francesc Candel, El Sant de la mare Margarida.

Miquel Rayó, El cami del far.

2001

Jordi Coca, Sota la pols.

Antoni Coll, Com una barca enmig de l'estany.

Pasqual Mas, La cara oculta de la lluna.

Nel.lo Navarro, La pantagruèlica guerra de Miquel Miracle.

Albert Gurt, Cendres sobre el mar.

Rafael Vallbona, La Comuna de Puigcerdà.

Vicenç Villatoro, La ciutat del fum.

2002

Vicent Pallarés, Les urpes del llop.

Sebastià Alzamora, Sara i Jeremies.

Emili Bayo, Projecte de felicitat.

2003

Jaume Cabré, Les veus del Pamano.

Toni Cucarella, Quina lenta agonia la dels ametlers perduts.

Emili Teixidor, Pa negre.

2004

Carme Riera, La meitat de l'ànima.

Josep M. Loperena, La casa del fanalet vermell.

Joaquim G. Caturla, L'home de l'estació.

Víctor Gómez Labrado, Quan anàvem a l'estraperlo.

Miquel Ferrà, El dia que Himmler va anar als toros.

2005

Francesc Gisbert, Els lluitadors.

Joan Garí, On dormen les estrelles. 
Lluís-Anton Baulenas, Per un sac d'ossos.

Maria Barbal, País intim.

2006

Albert Hernàndez, El tango de l'anarquista.

2007

Juli Alandes, Àcrates!

Jordi Coca, La noia del ball.

2008

Andreu Claret, El secret del brigadista.

2009

Carles Marin, Làngel del no-res.

2010

Víctor Gómez Labrado, La guerra de quatre.

Ferran Torrent, Bulevard dels francesos.

Enric Lluch, Després del silenci.

$2 \mathrm{OI} 2$

Empar Moliner, La col.laboradora.

Lluís Llach, Memòria d'uns ulls pintats.

Valentí Puig, Barcelona cau.

Sebastià Alzamora, Crim de sang.

Ferran Torrent, Ombres en la nit.

2013

Pep Coll, Dos taüts negres i dos de blancs.

Ivan Carbonell, La promesa del gal.lés.

Toni Cucarella, Dones d'aigua.

Margarida Aritzeta, El pou del maquis.

2014

Lluís Llach, Les dones de la principal.

Maite Salord Ripoll, L'alè de les cendres. 
JoAquim Espinós Felipe

Testimoniatge, actualització i fabulació: la memòria històrica de la Guerra Civil en la narrativa catalana actual

Nel.lo Navarro, Les mans $i$ altres relats de guerra.

Vicenç Villatoro Un home que sén va.

Maria Barbal, En la pell de l'altre.

2015

Guillem Martí, Cremeu Barcelona!

Juli Alandes, Trencatenebres.

Víctor G. Labrado, No mataràs.

Vicent Usó, Les veus i la boira.

Martí Domínguez, La sega.

2016

Agustí Colomer, A trenc d'alba.

2017

Margarida Aritzeta, La filla esborrada.

Joaquim Espinós, La presó del cel.

2018

Joan-Lluís Lluís, Jo sóc aquell que va matar Franco.

Xavier Aliaga, Les quatre vides de l'oncle Antoine. 